\title{
Multilineage Differentiation Potential of Bone and Cartilage Cells Derived from Explant Culture
}

\author{
Zareen Yameen ${ }^{1}$, David Leavesley ${ }^{1}$, Zee Upton ${ }^{1}$ and Yin Xiao ${ }^{2, *}$ \\ ${ }^{I}$ Tissue Repair and Regeneration Program, Institute of Health and Biomedical Innovation, Queensland University of \\ Technology, Brisbane, Australia and ${ }^{2}$ Institute of Health and Biomedical Innovation, Queensland University of Technol- \\ ogy, Brisbane, Australia
}

\begin{abstract}
To date, mesenchymal stem cells (MSCs) from various tissues have been reported, but the yield and differentiation potential of different tissue-derived MSCs is still not clear. This study was undertaken in an attempt to investigate the multilineage stem cell potential of bone and cartilage explant cultures in comparison with bone marrow derived mesenchymal stem cells (BMSCs). The results showed that the surface antigen expression of tissue-derived cells was consistent with that of mesenchymal stem cells, such as lacking the hematopoietic and common leukocyte markers (CD34, CD45) while expressing markers related to adhesion (CD29, CD166) and stem cells (CD90, CD105). The tissue-derived cells were able to differentiate into osteoblast, chondrocyte and adipocyte lineage pathways when stimulated in the appropriate differentiating conditions. However, compared with BMSCs, tissue-derived cells showed less capacity for multilineage differentiation when the level of differentiation was assessed in monolayer culture by analysing the expression of tissuespecific genes by reverse transcription polymerase chain reaction (RT-PCR) and histology. In high density pellet cultures, tissue-derived cells were able to differentiate into chondrocytes, expressing chondrocyte markers such as proteoglycans, type II collagen and aggrecan. Taken together, these results indicate that cells derived from tissue explant cultures reserved certain degree of differentiation properties of MSCs in vitro.
\end{abstract}

Key Words: Mesenchymal stem cells, cell differentiation, plasticity, multipotent, osteoblast, chondrocyte, adipocyte.

\section{INTRODUCTION}

Multipotent mesenchymal stem cells (MSCs) provide a fascinating model of differentiation [1,2], as well as a promising tool for cell therapy and treatment of a range of degenerative diseases [3, 4]. MSCs are considered to be quiescent, lacking tissue-specific characteristics and maintain this undifferentiated phenotype until they are exposed to appropriate signals $[5,6]$. MSCs have a capacity for extensive self renewal and maintain themselves throughout the life of an organism. They are "plastic" and under the influence of specific biological signals differentiate into specialized cells with a phenotype that is completely different from that of the precursor $[5,7]$. It is this property that MSCs can be exploited in multiple tissue repair and regeneration through therapeutic cell delivery.

Human bone marrow primarily serves as a reservoir for different populations of stem cells. It contains at least two types of stem cells: hematopoietic stem cells and mesenchymal stem cells (BMSCs) [8-16]. Despite the fact that bone marrow represents the main available source of MSCs, MSCs have been recently identified in numerous other mesenchymal tissues including trabecular bone [17-20], periosteum [21-24], adipose tissue [25-27], synovium [28, 29], skeletal muscle [30], lung [31] and deciduous teeth [32].

*Address correspondence to this author at the Institute of Health and Biomedical Innovation, Queensland University of Technology, Kelvin Grove Campus, Brisbane, Qld 4059 Australia; Tel: +61 73138 6240; Fax: +61 7 3138 6030; E-mail: yin.xiao@qut.edu.au
These tissue-derived cells have the capacity to differentiate into connective tissue cell lineages, including bone, fat, cartilage and muscle when placed in appropriate environments in vitro and in vivo [11,33-37]. However, it's impossible to draw a definite conclusion regarding the differentiation potential of tissue-derived cells due to the different methods used for cell isolation. Even though there is no specific cell surface marker for MSCs, a number of studies selected cell populations from tissue cultures based on the expression of Stro-1, CD105 and CD 106 [38, 39]. Therefore, the current study was undertaken in an attempt to compare the multilineage stem cell potential of tissue explant cultures of bone and cartilage. Bone marrow-derived MSCs (BMSCs) were used as a control and the cells derived from tissue explants of trabecular bone (hOB), cartilage (YCC) and alveolar bone (OBM) tissues were investigated side-by-side as sources of MSCs. Our studies revealed that MSCs isolated from tissue explant cultures had the potential to differentiate into multiple lineages, thereby indicating that these tissues may be alternative sources of mesenchymal stem cells via explant culture.

\section{MATERIALS AND METHODS}

\section{Isolation and Culture of Bone Marrow-Derived MSCs}

Fresh bone marrow samples ( $\mathrm{n}=7$, aged $65-70$ years old) were collected by aspiration from femoral canal during knee replacement operation at the Holy Spirit Northside Hospital, Brisbane QLD, Australia, in accordance with the institu- 
tional review board guidelines approved by the human research ethics committees of the Queensland University of Technology, The Prince Charles and The Holy Spirit Private Hospitals, Brisbane, QLD, Australia. After draining of synovial fluid, a femoral drill hole was made through the distal femur and an intramedullary rod was passed into the femoral canal. Marrow aspirates were collected by syringe. Mononuclear cells, which include the MSC population, were harvested using LymphoPrep ${ }^{\circledR}$ density gradient centrifugation. Briefly, 2-5 ml of bone marrow was collected in a $50 \mathrm{ml}$ tube containing $5 \mathrm{ml}$ phosphate buffered saline (PBS) supplemented with $200 \mathrm{U} / \mathrm{ml}$ Heparin (Invitrogen, Mount Waverley, VIC, Australia). Each sample was filtered through a 100 $\mu \mathrm{m}$ filter and $30 \mathrm{ml}$ PBS was added to the filtrate. The diluted cell suspension was carefully layered below LymphoPrep $^{\circledR}$ and was then centrifuged for 35 minutes at $400 \mathrm{~g}$, at $20^{\circ} \mathrm{C}$ without braking. The upper layer was aspirated leaving the mononuclear cell layer undisturbed at the interphase. The MSC-enriched low density fraction was collected carefully and rinsed with $20 \mathrm{ml}$ of control medium containing low glucose (LG; $1 \mathrm{~g} / \mathrm{l}$ glucose) Dulbecco's-Modified Eagles Media (DMEM; Invitrogen) with $10 \%$ fetal bovine serum (FBS; HyClone, Logan, Utah, USA), $10 \mathrm{U} / \mathrm{ml}$ penicillin and $10 \mu \mathrm{g} / \mathrm{ml}$ streptomycin (Invitrogen) by centrifugation at 200 $\mathrm{g}$ for 10 minutes at $20^{\circ} \mathrm{C}$. The resulting cell pellet was resuspended in DMEM and plated at $8 \times 10^{5}$ nucleated cells/T25 $\mathrm{cm}^{2}$ tissue culture flasks. MSC cultures were maintained at $37{ }^{\circ} \mathrm{C}$ in $5 \% \mathrm{CO}_{2}$, for 6 days before the medium was changed and thereafter the medium was changed every three days. When the cultures were $80-90 \%$ confluent, the cells were detached using $0.05 \%$ Trypsin-EDTA (Invitrogen) and replated at a density of $1.28 \times 10^{5}$ cells/T75 flask (termed passage 1) in low glucose DMEM containing $10 \%$ FBS and Penicillin/Streptomycin. When the MSC cultures were 80$90 \%$ confluent they were replated at a ratio of 1:3 for expansion under the same culture conditions and cryo-preserved in liquid nitrogen for later analysis.

\section{Isolation of Trabecular Bone and Cartilage-Derived Cells}

Samples of trabecular bone (hOB) and cartilage (YCC) $(n=7$, aged 65-70 years old) from the relatively healthy part of tibia of the same patients of marrow collection were obtained. Normal human alveolar bone specimens (OBM) $(n=5)$ were obtained from young, healthy patients aged from 12-16 years old at orthodontic clinic with ethics approval from the University of Queensland. Bone and cartilage pieces were cut into fragments of size 3-8 mm, cleaned of adherent connective tissue, rinsed well and placed directly into six-well culture plates containing high glucose (HG; $4.5 \mathrm{~g} / 1$ glucose) DMEM (Invitrogen) supplemented with $10 \%$ FCS (HyClone), $10 \mathrm{U} / \mathrm{ml}$ penicillin and $10 \mu \mathrm{g} / \mathrm{ml}$ streptomycin (Invitrogen). Confluent monolayers of fibroblast-like cells were obtained after 10-20 days and were passaged once in $25 \mathrm{~cm}^{2}$ flasks until confluent. The cells were then cryopreserved for later analysis. All cultures from individual donors were maintained separately.

\section{FACS Analysis}

Analysis of cell surface molecules was performed following the procedure reported by Pittenger [14] and Majumdar [40]. Briefly cells (passage 5) were trypsinized, washed with
PBS and in FACS buffer (2\% BSA, $0.1 \%$ sodium azide in PBS $)$ and aliquots of cells $\left(1 \times 10^{6}\right)$ were incubated at $4{ }^{\circ} \mathrm{C}$ for 30 minutes with antibodies against CD29, CD34, CD45, CD90, CD105 and CD166 (BD Biosciences, North Ryde, NSW, Australia). Subsequently, secondary antibody IgG1 (fluorochrome-conjugated) was added and incubated at room temperature for 15 minutes. Analysis of the cell surface antigens was performed with a FACS Calibur Cytometer (BD Biosciences, San Jose, CA, USA). Controls for the FACS procedures included conditions where the primary antibody was omitted. In addition, an anti- human IgG1 antibody (BD Biosciences) was used.

\section{Osteogenic, Chondrogenic and Adipogenic Differentiation}

Differentiation experiments were performed on cultures recovered from frozen stocks at passages 2-6. The cells were grown to confluence and then subjected to specific differentiating conditions as described below. The differentiation assay was carried out in triplicate in six-well culture plates with all samples of BMSCs $(n=7)$, hOB $(n=7)$, YCC $(n=7)$ and OBM $(\mathrm{n}=5)$.

\section{Osteogenic Differentiation}

Osteogenic differentiation of subconfluent MSCs from bone marrow and explant tissue-derived monolayers was induced by transfer to high glucose DMEM (HG DMEM) medium containing $10 \%$ FBS, $50 \mu \mathrm{M}$ ascorbic acid 2phosphate, $10 \mathrm{mM} \beta$-glycerol phosphate and $100 \mathrm{nM}$ dexamethasone (Sigma Aldrich, Castle Hill, NSW, Australia) in HG DMEM. After four weeks, calcium phosphate mineral deposition was visualized by von Kossa staining.

\section{Chondrogenic Differentiation}

Chondrogenic medium consists of serum-free medium consisting of HG DMEM supplemented with $10 \mathrm{ng} / \mathrm{ml}$ TGF$\beta 3$ (Chemicon, Boronia, VIC, Australia), $100 \mathrm{nM}$ dexamethasone (Sigma Aldrich), $50 \mu \mathrm{g} / \mathrm{ml}$ ascorbic acid 2phosphate (Sigma Aldrich), $100 \mu \mathrm{g} / \mathrm{ml}$ sodium pyruvate (Invitrogen), $40 \mu \mathrm{g} / \mathrm{ml}$ proline (Sigma Aldrich) and ITS-plus (BD Biosciences; final concentrations: $6.25 \mu \mathrm{g} / \mathrm{ml}$ insulin, $6.25 \mu \mathrm{g} / \mathrm{ml}$ transferrin, $6.25 \mu \mathrm{g} / \mathrm{ml}$ selenous acid, $5.33 \mu \mathrm{g} / \mathrm{ml}$ linoleic acid and $1.25 \mathrm{mg} / \mathrm{ml}$ bovine serum albumin). After four weeks, the differentiated monolayers were stained with Alcian Blue (Sigma Aldrich) for visualization of proteoglycan deposition.

Cells were also cultured as a micromass pellet of cells, created by gentle centrifugation [36]. To initiate the chondrogenic culture, aliquots of $5 \times 10^{5}$ cells were suspended in $0.5 \mathrm{ml}$ of chondrogenic media with TGF- $\beta 3$ (with the rest of the supplements described above) and centrifuged at $600 \mathrm{~g}$ for 5 mins in a $15 \mathrm{ml}$ polypropylene conical tube. The cells were left at the bottom of the tube and placed in a $37^{\circ} \mathrm{C} \mathrm{CO}_{2}$ incubator with loosened caps permitting gas exchange. The medium was replaced three times a week. After 3 weeks the cell pellets were washed in PBS, fixed in $4 \%$ paraformaldehyde and embedded in paraffin. The pellets were sectioned ( $5 \mu \mathrm{m}$ thickness) and analyzed for the expression of proteoglycans using Alcian Blue stain. Immunohistochemical studies were carried out on the pellet sections to detect chondrocyte specific proteins such as aggrecan (AGG) and type II collagen (Col-II). 


\section{Adipogenic Differentiation}

Cells from passages 2-6 were treated for 3 days with adipogenic induction medium containing $0.5 \mathrm{mM}$ isobutylmethyl xanthine (Sigma Aldrich), 100-200 $\mu \mathrm{M}$ indomethacin (Sigma Aldrich), $1 \mu \mathrm{M}$ dexamethasone, $10 \mu \mathrm{g} / \mathrm{ml}$ insulin (Invitrogen) in HG DMEM with 10\% FBS, and then the medium was changed to adipogenic maintenance medium (HG DMEM with FBS and insulin) for $24 \mathrm{hrs}$. After the three cycle schedule of 3 days in inducing medium and 1 day in maintenance medium, cells were grown in adipogenic maintenance medium for another 7 days, with the change of medium every three days. Cells were then washed with PBS, fixed with 4\% paraformaldehyde and stained with Oil Red O (Sigma Aldrich) to detect lipid.

\section{Histological and Immunocytochemical Analysis}

\section{Histological Analysis}

The osteogenic-differentiated cells were fixed initially with 4\% paraformaldehyde in PBS at $\mathrm{pH} 7.4$ for 15 minutes. The mineralized matrix was evaluated by von Kossa staining. Cartilage matrix deposition by chondrogenic-differentiated cells cultured in six-well plates was identified by the staining of Alcian Blue. Adipogenic cells were detected using Oil red $\mathrm{O}$ staining to visualize the oil droplets.

\section{Immunocytochemical Analysis}

Chondrogenic differentiation was also evaluated by 3dimensional pellet culture. The cell pellets were fixed in $4 \%$ paraformaldehyde and then embedded in paraffin blocks. Blocks were cut into 5- $\mu \mathrm{m}$ sections. For immunocytochemical analysis, cell sections were incubated with $3 \%$ hydrogen peroxide $\left(\mathrm{H}_{2} \mathrm{O}_{2}\right)$ for $15 \mathrm{~min}$ to eliminate endogenous peroxidase activity. Non-specific protein binding in the sections was blocked by $10 \%$ swine serum (DakoCytomation, Botany, NSW, Australia) in PBS containing $0.1 \%$ bovine serum albumin (BSA; Sigma Aldrich) and sodium azide $\left(\mathrm{NaN}_{3}\right.$; Sigma Aldrich). Sections were incubated with optimal dilu- tion (1: 10) of primary antibodies for collagen type II and aggrecan (Chemicon) overnight at $4{ }^{\circ} \mathrm{C}$. Sections were then incubated with a biotinylated swine-anti-mouse, rabbit, goat secondary antibody (DAKO Multilink; DakoCytomation) for 15 minutes and then incubated with horse radish peroxidaseconjugated avidin-biotin complex (DAKO Multilink; DakoCytomation) for 15 minutes. Antibody complexes were visualized after the addition of a buffered diaminobenzidine (Sigma Aldrich) substrate for 3 minutes. The reaction was stopped by immersion and rinsing the sections in PBS. The sections were then counterstained with Mayer's hematoxylin (Sigma Aldrich) for 15 seconds and were rinsed in tap water for 5 minutes. Finally, the sections were dehydrated in ascending concentrations of ethanol solutions, cleared in xylene and mounted with coverslips using DePeX mounting medium (Labtek, Brendale, QLD, Australia).

Total RNA Isolation and Reverse Transcriptase-Polymerase Chain Reaction (RT-PCR) Analysis

Total RNA was extracted from 28 day cultures (cell monolayers and 3-D pellets) using Tri Reagent (Sigma Aldrich) as per the manufacturer's protocol and total RNA concentration was determined spectrophotometrically. The mRNA was reverse transcribed to first strand cDNA from 1 $\mu \mathrm{g}$ RNA for a $20 \mu \mathrm{l}$ reverse transcription reaction using $\mathrm{Su}-$ perScript III reverse transcriptase (200 units/ $\mu 1$, Invitrogen) with Oligo dT as the primer.

Expression of the specific mRNAs relative to the osteogenic lineages [alkaline phosphatase (ALP), type I Collagen (Col-I), osteopontin (OPN), osteocalcin (OCN)], chondrogenic lineages [type II collagen (Col-II), and aggrecan (AGG)] and adipogenic lineages [peroxisome proliferatoractivated receptor $\gamma 2$ (PPAR $\gamma 2$ ), fatty acid binding protein (AP2)] were examined by RT-PCR. Beta-2 Microglobulin $(\beta 2 \mathrm{M})$ was used as a control for the RT-PCR analysis. PCR was performed using $2 \mu \mathrm{l}$ cDNA, $1 \mathrm{U}$ of Red Taq DNA polymerase (Sigma Aldrich) and $10 \mathrm{pM}$ of each primer (Table 1) in a $20 \mu 1$ reaction mixture for $31-35$ cycles to make sure

Table 1. Primers for RT-PCR

\begin{tabular}{|c|c|c|c|}
\hline \multicolumn{4}{|c|}{ Osteogenic Primers: } \\
\hline Col- I & 5 'CTTTGGAGCCAGCTTGGA 3' & 5' GTGGGCTTCCTGGTGA 3' & 450 \\
\hline OPN & 5 ' CCAAGTAAGTCCAACGAAAG 3' & 5' GGTGATGTCCTCGTCTGTA 3' & 347 \\
\hline \multicolumn{4}{|c|}{ Chondrogenic Primers } \\
\hline Col- II & 5' GGTGAAGAAGGCAAGAGA 3' & 5' CAGCACCTGTCTCACCA3' & 280 \\
\hline AGG & 5' AGACTTGGTGGGGTCAG 3' & 5' GATGTTTCCCCACTAGTG 3' & 450 \\
\hline \multicolumn{4}{|c|}{ Adipogenic Primers } \\
\hline$\beta 2 \mathrm{M}$ & 5' CCCCCACTGAAAAAGATGAG 3' & 5' TCACTCAATCCAAATGCGGC 3' & 102 \\
\hline
\end{tabular}


that amplification was in the linear range for each primer pair. Each cycle consisted of $94{ }^{0} \mathrm{C}$ of denaturation for 1 minute, $53{ }^{\circ} \mathrm{C}$ of annealing for 30 seconds and $72{ }^{0} \mathrm{C}$ of extension for 30 seconds. Following PCR, the amplified lineage specific transcripts were electrophoresed in $2 \%$ agarose gel to enable visualization of the PCR products. The relative density of PCR products was measured using NIH Image V1.62 to analyze one dimensional electrophoretic gel and the expression level of each gene was calculated relative to beta2-microglobulin.

\section{Statistical Analysis}

Unless otherwise stated, all results were based on data generated from triplicate studies of each sample of seven BMSCs, hOB, and YCC samples, and five OBM samples. Statistics were analyzed using one-way ANOVA and SNK-q statistical tests from the statistical package SPSS v14 (Chicago, IL). The significant difference was considered at $\mathrm{p}<0.05$.

\section{RESULTS}

\section{Growth and Morphology of BMSC and Tissue-Derived Cells}

BMSC fractions from density gradient centrifugation failed to spread, migrate or proliferate when cultured in high glucose media (HG DMEM) containing 10\% FBS. However, when cultured in low glucose media (LG DMEM), numerous fibroblast-like cells were observed in the culture. Therefore, BMSC fractions from density gradient centrifugation were cultured in low glucose media (LG DMEM) containing $10 \%$ FC and numerous fibroblast-like cells were observed after 7 days in the culture. Subsequently, these cells formed
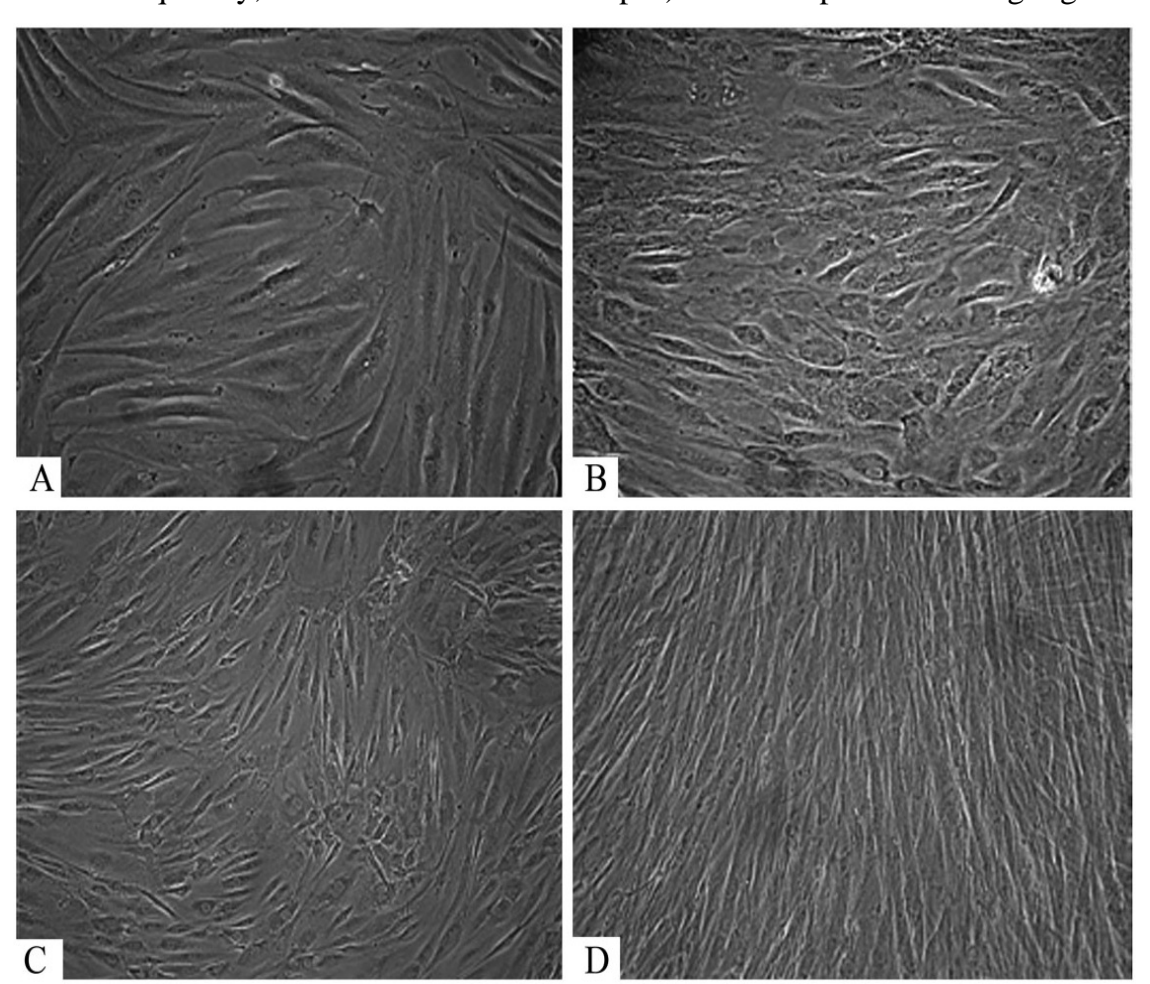

Fig. (1). Morphology of primary cells cultured in their respective media for 2 weeks. (A) Bone marrow-derived MSCs in low glucose DMEM isolated by density gradient centrifugation; and (B) trabecular bone chip- derived cells (hOBs), (C) cartilage- derived cells (YCCs) and (D) alveolar bone-derived cells (OBMs) in high glucose DMEM (magnification $=200$ times). colonies which expanded to form MSC-like fibroblastoid cells occupying the entire plastic surface of the culture vessel. Initially, the isolated adherent BMSCs were observed as heterogeneous groups of cells and later became homogeneous as the cells continued to proliferate based on cell morphology. The primary cultures were maintained for 12-16 days before they were detached by trypsinization and subcultured. Cells from the second passage (P2) demonstrated a fibroblast-like, spindle-shaped morphology when viewed under phase contrast microscopy (Fig 1A). All BMSC samples could be expanded over 24 population doublings ( 8 passages), but in the 8th passage (P8), the spindle or bipolarshaped BMSCs began to display a broadened, flat morphology. The cells also showed a distinctive swirly pattern when confluent that was consistent with previous findings [41]. About $95-98 \%$ of the isolated BMSCs were phenotypically homogeneous when confluent, as determined by their fibrorow-derived cells have morphologic characteristics of MSCs.

Explant cultures from trabecular bone, alveolar bone and cartilage were maintained in HG DMEM supplemented with $10 \% \mathrm{FCS}$ and penicillin/streptomycin (Invitrogen). After one week of cultivation, hOBs, YCCs and OBMs also yielded numerous fibroblast-like cells (as shown in Fig. 1B, C, D) that subsequently expanded to occupy the whole plastic surface of the culture vessel. Phase contrast microscopy also revealed similar BMSC-like swirly patterns of cell growth among the tissue derived-cells (data not shown). All these tissue-derived cells were able to be explanted over 24 population doubling (8 passages). Furthermore, in contrast to other cell types, OBMs exhibited rapid proliferative potential and became $95 \%$ confluent within 3-4 days of passage (1:3 split) when expanded in high glucose media, while other blastic shape. The results indicate that all of these bone mar- 
types of cells required 8-10 days to reach $95 \%$ confluence after passage (1:3 split).

\section{FACS Analysis}

Immunophenotype analysis of BMSC and explantderived cells was determined using FACS. Flow cytometric analyses demonstrated that BMSCs and explant-derived cells similarly expressed typical MSC specific antigens CD29, CD90, CD105, CD166, and were negative for the early hematopoietic marker and lymphocytic markers CD34, CD45 respectively (Fig. 2).

\section{In Vitro Differentiation Studies of BMSCs and the Tissue- Derived Cells into Osteoblasts, Chondrocytes and Adipo- cytes}

To investigate and establish the differentiation potential, the passage 2 and passage 6 of various tissue-derived cells and BMSCs were placed at a density of $2.7 \times 10^{4}$ cells $/ \mathrm{ml}$ in a six-well plate and cultured under appropriate conditions to induce lineage specific differentiation. Bone-derived, cartilage-derived and alveolar bone-derived explant cultures were assayed in parallel. For osteogenic differentiation, cells were cultured in monolayers in the presence of osteogenic supplements and acquired an osteoblastic morphology with the deposition of mineralized extracellular matrix as demonstrated with von Kossa staining (Fig. 3). No mineralized matrix could be detected in the undifferentiated cultures, which were maintained in culture medium alone. Within $2-4$ weeks BMSCs showed gradual deposition of calcium nodule formation in the cell culture, which covered the entire vessel surface after four weeks. All tissue-derived cells exhibited an osteoblast phenotype with the detectable matrix mineralization. However, the bone nodule size and number in tissuederived cells were much less than BMSCs in osteogenic culture. The osteoblastic phenotype was further assessed by measuring the expression of alkaline phosphatase (ALP), collagen I (Col I), osteopontin (OPN) and osteocalcin (OCN) using RT-PCR (Fig. 4A) in all samples. All these osteogenic markers were detectable in all four cell types during 2-4 week osteogenic culture. Variation was detected in the mRNA expression level of these markers in each individual sample. For example in the sample presented in Fig. (4A), YCC showed less mRNA expression of Col-I and OPN and BMSCs showed less expression of OCN. However, no statistically significant difference was found in these gene expression amount BMSC, hOB, YCC and OBM in 28 days of osteogenic induction, when all samples $(\mathrm{n}=7)$ were summarized and normalized with the house keeping gene $(\beta 2 \mathrm{M})$ $(\mathrm{p}>0.05)$ (Fig. 4).

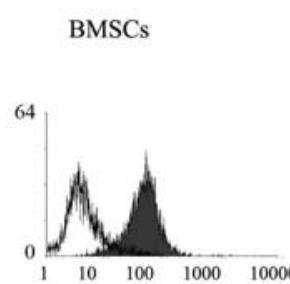

$$
\text { hOBs }
$$

OBMs

YCCs
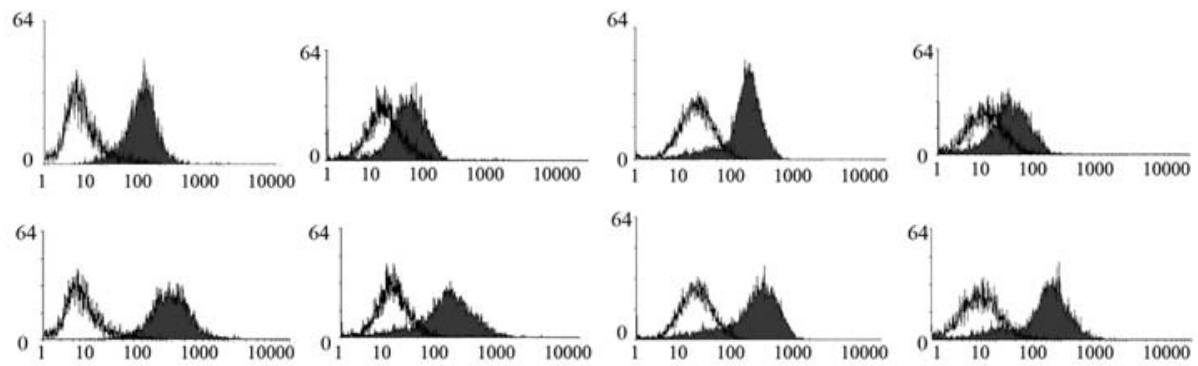

CD166
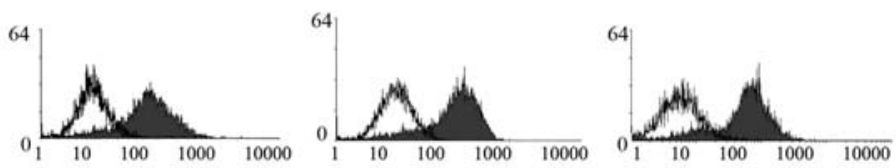

CD105
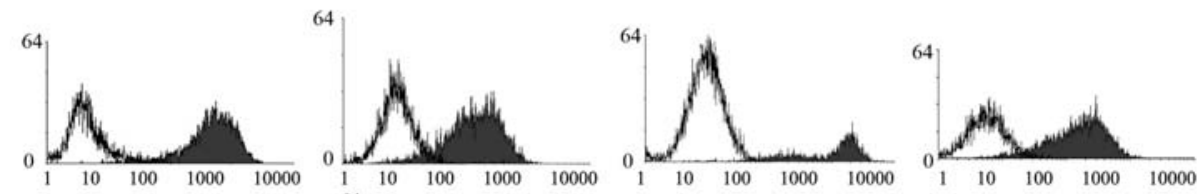

CD90
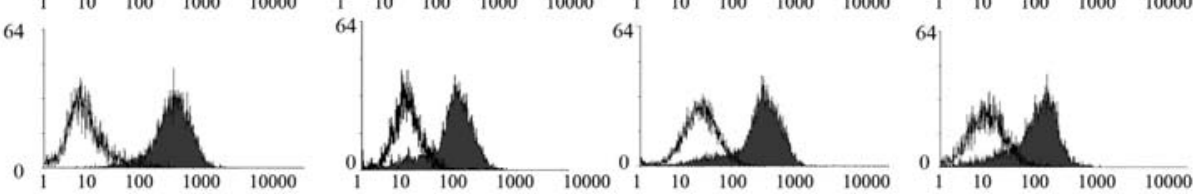

CD29
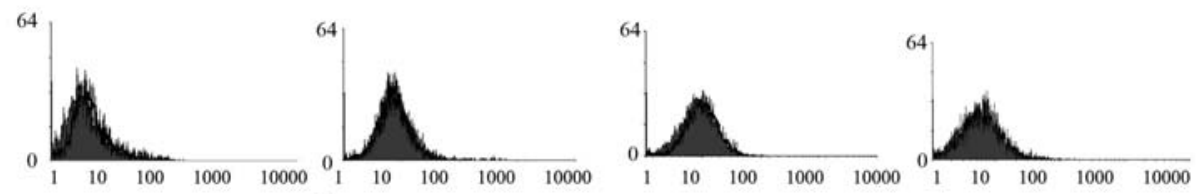

CD34
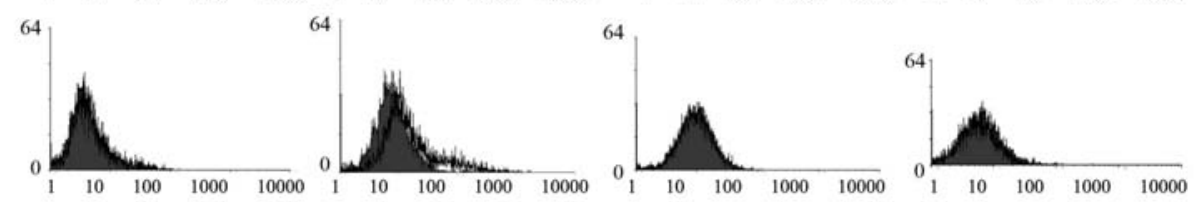

CD45

Fig. (2). Analysis of different cell preparations of MSCs, hOBs, OBMs and YCCs for the expression of surface antigens by flow cytometry. Cells were cultured for 5 passages, harvested and labelled with antibodies against human antigens CD166, CD105, CD90, CD45, CD34 and CD29 indicating both positive for CD 166, CD105, CD29, CD90 and negative for CD34 and CD45. 
Control
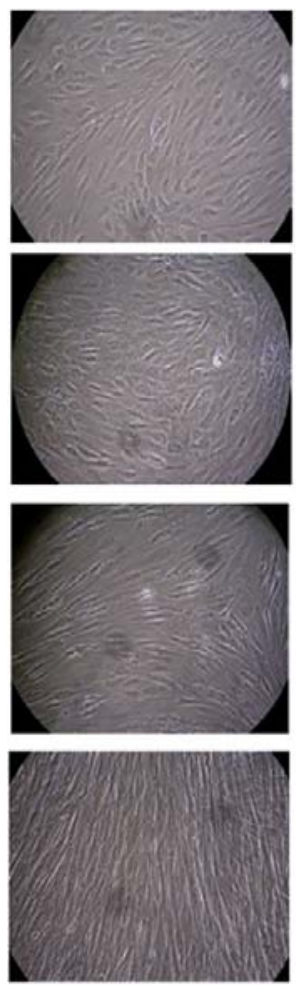

Osteogenic
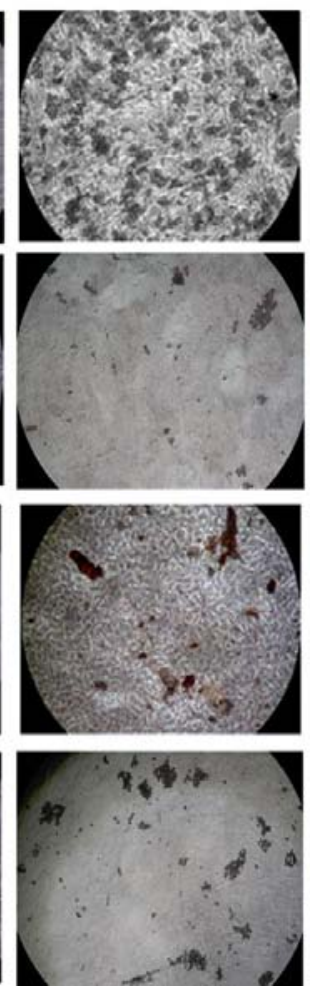

Chondrogenic
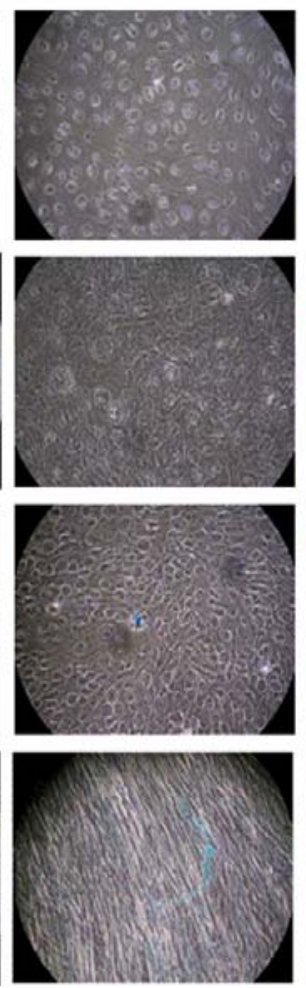

Adipogenic
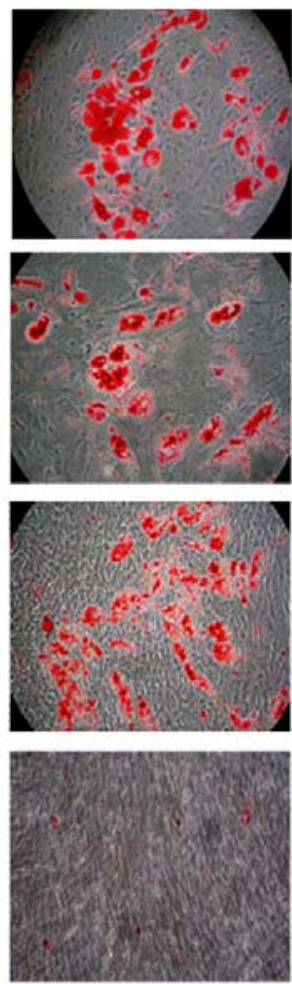

YCC

\section{BMSC}

hOB

OBM

Fig. (3). Histological analyses by phase contrast microscopy in bone marrow derived MSCs (BMSCs) and tissue-derived cells-trabecular bone (hOBs), cartilage cell (YCCs) and alveolar bone cells (OBMs). Cells in monolayer cultures in six-well plates were tested for their ability to differentiate in vitro to multiple lineages for 28 days. Osteogenesis was indicated by the calcium deposition producing a mineralized matrix that was detected by von Kossa staining. Chondrogenesis was shown by staining with Alcian Blue. Adipogenesis was indicated by the accumulation of lipid vacuoles that stained with Oil Red O. In untreated cell cultures there was an absence of such phenotypes (magnification $=200$ times $)$.

Chondrogenic differentiation in monolayers was promoted in early passages of all samples subjected to serumfree chondrogenic medium containing TGF 33 . Under this condition the tissue-derived cells and the BMSCs lost some of their fibroblastic morphology and acquired the polygonal or cuboidal morphology of a typical chondrocyte (Fig. 3). YCC, along with the BMSCs, exhibited a typical chondrocyte phenotype, but hOB and OBM showed less polygonal morphological changes in 4 weeks chondrogenic culture (Fig. 3). After 28 days the chondrocytic phenotype was further confirmed by the expression of collagen type II (Col II) and aggrecan (AGG) using RT-PCR (Fig. 4B) in all differentiated BMSCs and tissue-derived cells, with no expression in the controls (data not shown). A significantly lower expression of Col II and AGG in OBM was observed in comparison to YCC $(\mathrm{p}<0.05)$.

Chondrogenic differentiation was further evaluated in micromass culture for 3-4 weeks in serum-free chondrogenic medium supplemented with TGF 33 . Sections $(5 \mu \mathrm{m})$ of 3week old cultures were processed for histological analysis. Within the sections, depositions of sulphated proteoglycans were stained blue by Alcian Blue (Fig. 5A). Immunocytochemical studies also revealed that the major components of the extracellular matrix (ECM) in the chondrogenic micromass cultures were Col II and AGG as shown by the brown color in the sections (Fig. 5A). RT-PCR results also confirmed the expression of Col II and AGG mRNA as observed in immunocytochemical analysis. There was less expression of Col-II and AGG in BMSCs and hOB pellet cultures compared with YCC (Fig. 5B). However, no significant difference in both Col-II and AGG expression amongst BMSC, hOB and YCC in chondrogenic micromass culture, when all samples $(n=7)$ were summarized and normalized to the house keeping gene $(\beta 2 \mathrm{M})(\mathrm{p}>0.05)$ (Fig. 5).

The adipogenic potential of early passages of BMSCs and explant tissue-derived cells was assayed after inducing adipogenic differentiation. After 4 week of induction, the cell morphology changed and accumulation of lipid rich vacuoles were observed as visualized by oil red $\mathrm{O}$ staining (Fig. 3). OBM showed the lowest level of staining for lipid. However, after 4 weeks of induction the adipocyte specific peroxisome proliferators-activated receptor $\gamma_{2}(\mathrm{PPAR} \gamma 2)$ and fatty acid binding protein (AP2) were determined by RTPCR (Fig. 4C) and found to be expressed in BMSCs and all tissue-derived cells (Fig. 4).

\section{DISCUSSION}

Despite the fact that bone marrow aspirates have been considered to be the most accessible and enriched source of MSCs [18] autologous bone marrow procurement has limitations. For reasons that are not apparent, there have been variable problems in isolating BMSCs. The number and proliferative capacity of BMSCs depends on donor age, disease 


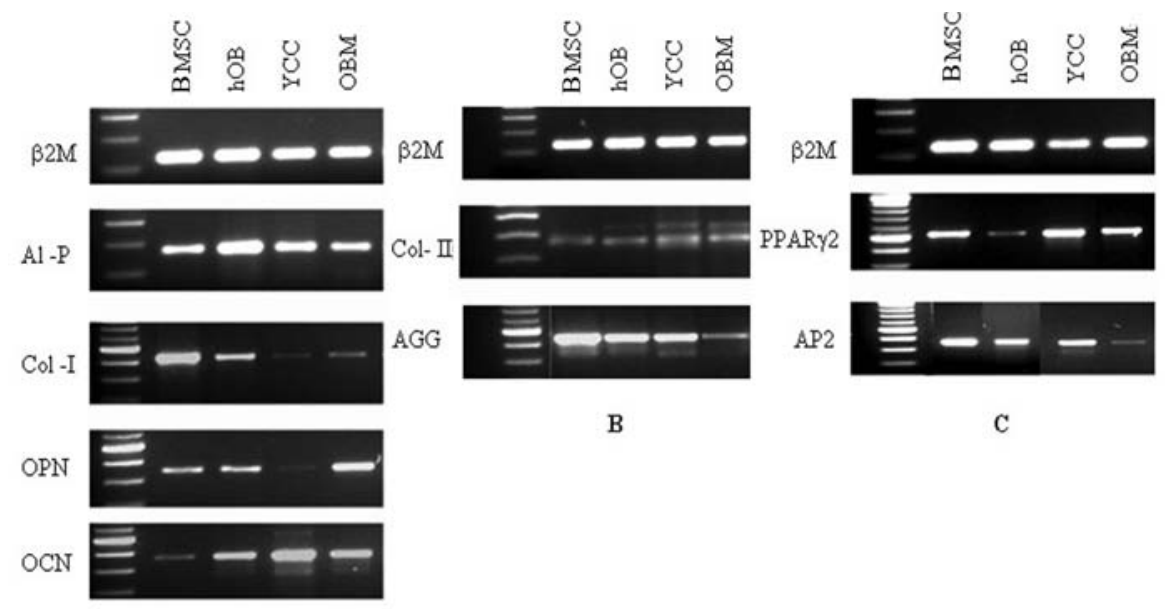

A

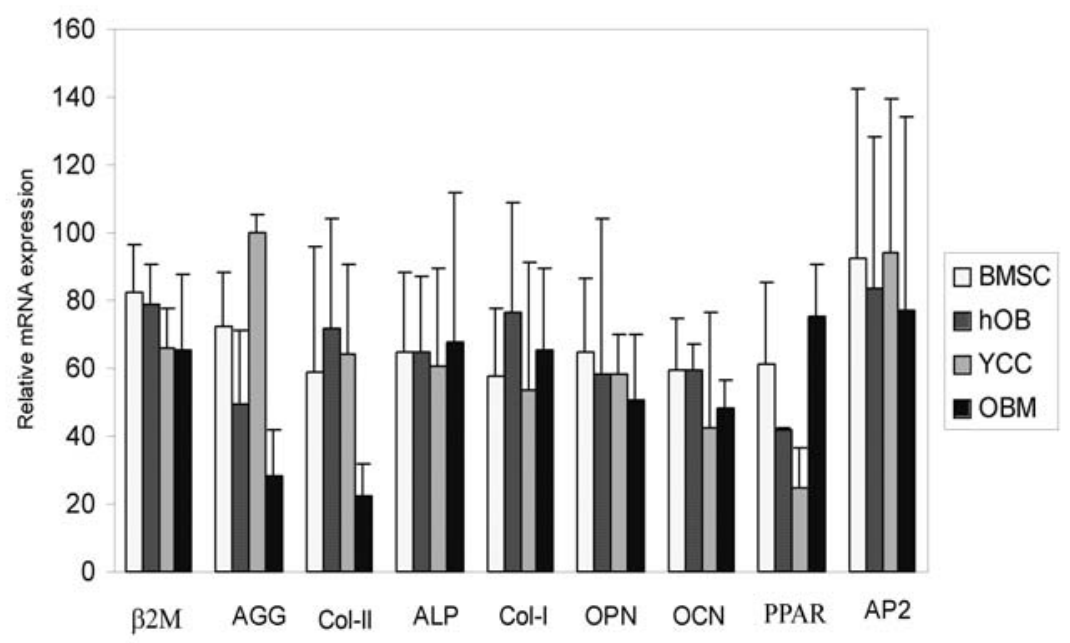

Fig. (4). RT-PCR analyses of mRNA expression of lineage specific genes in osteogenic, chondrogenic and adipogenic cultures in bone marrow-derived MSCs and tissue-derived cells (hOBs, YCCs and OBMs). A. Under osteogenic conditions cells expressed the osteoblast related genes; alkaline phosphatase (ALP: 180 bps), collagen I (Col -I: 450 bps), osteopontin (OPN: 347 bps) and osteocalcin (OCN: 346 bps). B. Chondrogenic differentiation of monolayers with TGF- $\beta 3$ expressed cartilage specific genes- collagen II (Col-II: 280 bps), and aggrecan (AGG: 450 bps). C. The cells treated with adipogenic supplements expressed the adipocyte specific genes peroxisome proliferator-activated receptor (PPAR $\gamma$ 2: $550 \mathrm{bps)}$ and fatty acid binding protein (AP2: $241 \mathrm{bps)}$. In all these PCR reactions, $\beta$-2-microglobulin ( $\beta 2 \mathrm{M}$ : $102 \mathrm{bps}$ ) was used as a control for RT-PCR. The graph shows the relative expression level of each gene in relation to the expression of $\beta$-2microglobulin.

history and the volume of marrow aspirates obtained [19, 32]. MSCs residing in diverse mature host tissues have recently been recognized $[28,29]$, hence potentially providing alternative sources of MSCs for both basic research and clinical application. In view of this, we compared and characterized tissue-derived (trabecular bone, cartilage and alveolar bone) MSCs using explant culture method with the properties of bone marrow-derived MSCs to evaluate the differential potential of these cells. This study demonstrated that the MSCs harvested from explant culture of committed tissues shared a commonality with bone marrow-derived cells in terms of morphology and immunophenotype. The expression of molecular differentiation markers and their phenotypic potential to differentiate into multiple mesenchymal cell lineages in vitro were demonstrated in tissuederived explant cultures. Thus, cells from tissue-derived ex- plant cultures possessed certain degree of typical stem cell properties such as being multipotent and able to self renew.

In our experiments the tissue-derived cells were isolated through explant cultures without treating the tissues with any external enzymatic digestion as reported by others [17]. This explant culture method isolated the cells from cartilage and bone depending on the cell potential to migrate out of the bone and cartilage. These cells showed fibroblastic spindle shape similar to BMSCs and expressed typical MSC cell surface markers, negative for CD45 and CD34 and positive for CD29, CD90, CD166, and CD105 (SH2) [42]. Although it is well know that bone marrow-derived MSCs have great proliferation capacity, in the present study the expansion ability of tissue-derived cells showed similarly to that of BMSCs. Tissue-derived and marrow-derived MSCs were both able to be explanted for at least 24 population doublings 
Control
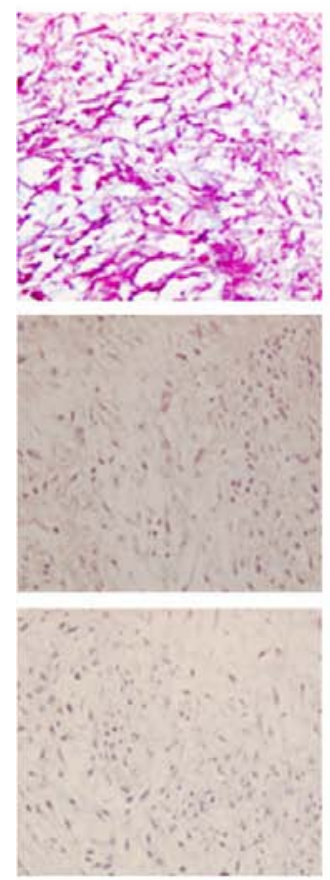

BMSC
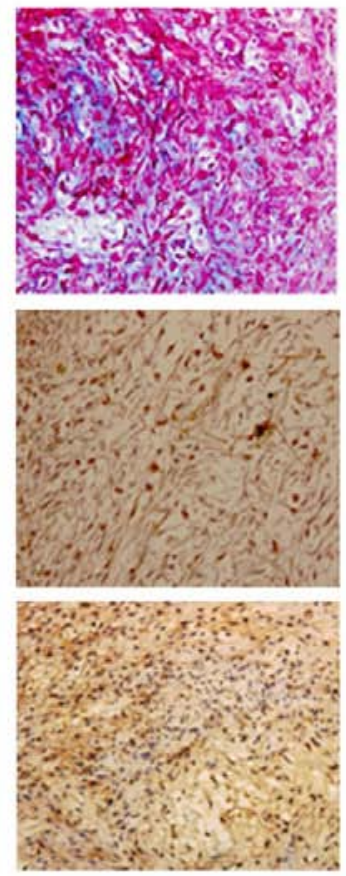

hOB
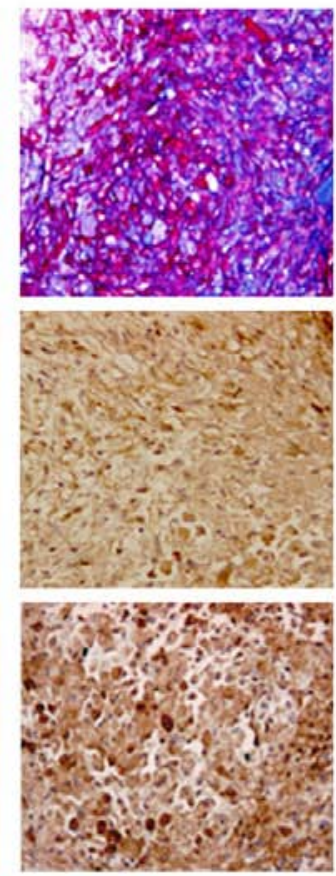

YCC

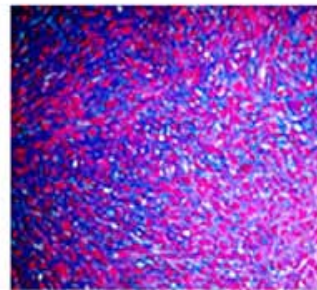

Alcian Blue
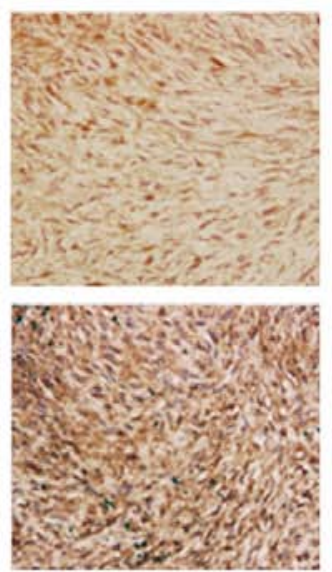

Col-II

AGG
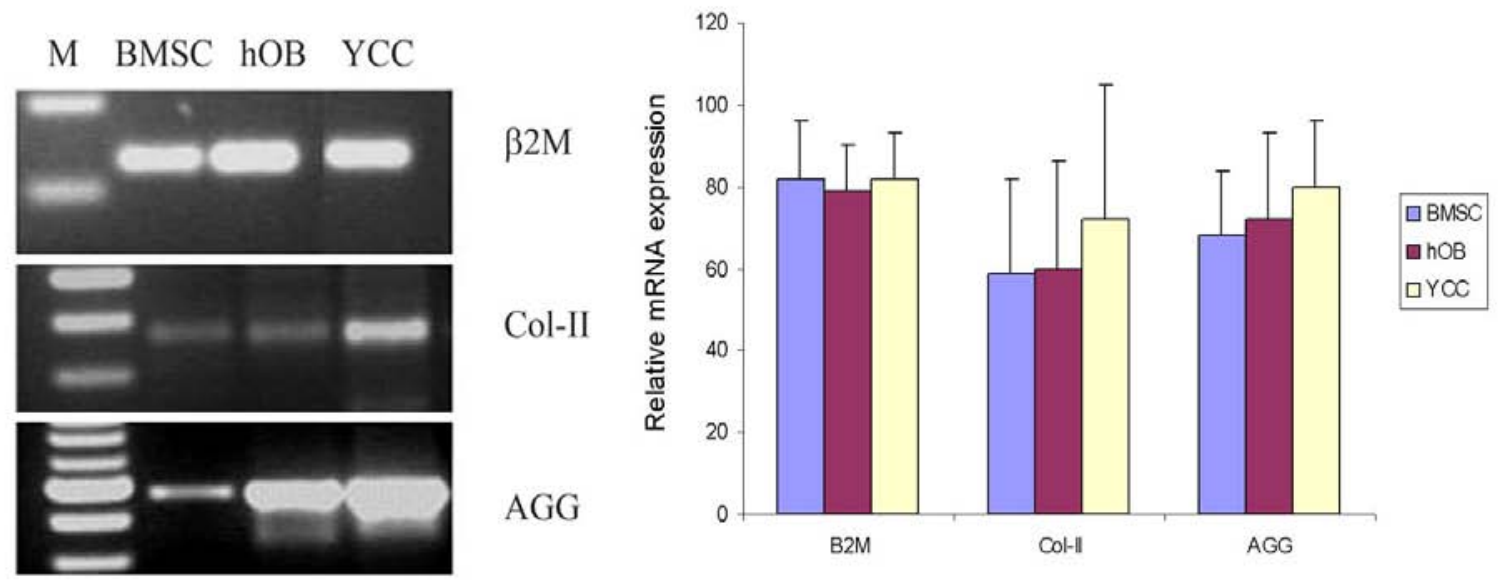

Fig. (5). Chondrogenesis was determined in micromass pellet cultures using bone marrow-derived MSCs, tissue-derived cells (hOBs and YCCs). Cells $(500,000)$ were subjected to low-speed $(600 \mathrm{~g})$ centrifugation and the cell mass was cultured in defined chondrogenic media with TGF- $\beta 3$ for 21 days. Chondrogenesis was evaluated by the accumulation of proteoglycans staining with Alcian Blue (5A, magnification $=200$ times). Micromass pellet cultures showing morphological changes were subject to immunohistological analysis with an antibody specific for Col-II and AGG (5A A, magnification = 200 times). In control sections there was an absence of such phenotypes. All samples were cultured in pellet format for 28 days in the presence of TGF- $\beta 3$ prior to recovery of total RNA and PCR analysis. 3D-Chondrogenic differentiation resulted in cells that expressed cartilage specific genes (Col-II and AGG) (Fig. 5B). $\beta$-2-microglobulin is used as a control for RTPCR. The graph shows the relative expression level of each gene in relation to the expression of $\beta$-2-microglobulin.

(8 passages) with similar kinetics of cell growth. The highest self-renewal capacity was noted in OBM, which may in part be explained by the fact that these cells were derived from alveolar bone specimens from patients with a younger age. These data, in turn, suggested that the cells that migrated out of the tissue explants had similar characteristics in culture to bone marrow-derived MSCs.
The multilineage differentiation capacity of the tissuederived cells was assessed by the phenotypical expression of extracellular matrix and differentiation genes relative to mesenchymal cell lineages: osteogenic, chondrogenic and adipogenic. In general tissue-derived cells were able to be differentiated into osteoblasts, chondrocytes and adipocytes because the extracellular matrix and differentiation genes 
typical for differentiated osteogenic, chondrogenic, and adipogenic cells have been detected. However, histologically greater calcium deposition and hence greater osteogenic differentiation potential was observed with the BMSCs compared to the tissue-derived MSCs as detected by von Kossa stain. Moreover, cells derived from cartilage showed a tendency of less mRNA expression of Col-I and OPN compared with cells derived from bone in the osteogenic condition. Interestingly OBM showed lower differentiation capacity into chondrocytes and adipocytes despite OBM was derived from younger aged patients compared with other tissue derived cells, which indicates that age may not be the only determinant of differentiation capacity of tissue-derived cells. We have also demonstrated that tissue-derived cells can be cultured in high density pellet culture in a serum-free chemically defined medium containing TGF $\beta 3$; a property shared with BMSCs $[36,43,44]$. The mass of the tissue increased over a period of 3 weeks as shown for the BMSCs. The deposition of cartilage matrix such as proteoglycans was detected in the mass culture of tissue-derived cells. Furthermore, RT-PCR analysis of cells in the micromass pellet revealed the expression of the chondrogenic specific marker genes Col II, and AGG, demonstrating the cartilage phenotype of these pellets in the chondrogenic media. These data regarding mesenchymal differentiation lead us to suggest that tissue-derived cells retain some degree of plasticity and their differentiation capacity is more dependent on their microenvironment and less dependent on their primitive status $[32,45]$.

In summary, our data indicates that MSCs can be sourced not only from bone marrow, but also from other readily available sources like trabecular bone, alveolar bone and cartilage via explant culture. However, mesenchymal stromal cells isolated from other sources are less potent than bone marrow derived MSCs.

\section{ACKNOWLEDGEMENT}

The authors thank the medical doctors and especially Prof. Ross Crawford (Department of Orthopedics, The Prince Charles and The Holy Spirit Hospital, Australia) for help with the femoral bone marrow sample collection. We would also like to thank Mr. Don Geyer for his expert assistance in making paraffin blocks of cell pellets and sections for histology. We thank Dr. Gary Brook and Mrs. Sanjleena Singh for their help with the Flow Cytometry. This research was supported by the Bone Strategic Collaborative Fund of Queensland University of Technology.

\section{REFERENCES}

[1] Sekiya I, Larson BL, Vuoristo JT, Cui JG, Prockop DJ. Adipogenic differentiation of human adult stem cells from bone marrow stroma (MSCs). J Bone Miner Res 2004; 19: 256-64.

[2] Sekiya I, Vuoristo JT, Larson BL, Prockop DJ. In vitro cartilage formation by human adult stem cells from bone marrow stroma defines the sequence of cellular and molecular events during chondrogenesis. Proc Natl Acad Sci USA 2002; 99: 4397-402.

[3] Hoogduijn MJ, Gorjup E, Genever PG. Comparative characterization of hair follicle dermal stem cells and bone marrow mesenchymal stem cells. Stem Cells Dev 2006; 15: 49-60.

[4] Jorgensen C, Gordeladze J, Noel D. Tissue engineering through autologous mesenchymal stem cells. Curr Opin Biotechnol 2004; 15: 406-10.

[5] Barry FP. Biology and clinical applications of mesenchymal stem cells. Birth Defects Res C Embryo Today 2003; 69: 250-6.
[6] Tuan RS, Boland G, Tuli R. Adult mesenchymal stem cells and cell-based tissue engineering. Arthritis Res Ther 2003; 5: 32-45.

[7] Caplan AI, Bruder SP. Mesenchymal stem cells: building blocks for molecular medicine in the 21 st century. Trends Mol Med 2001; 7: 259-64.

[8] Bianco P, Gehron Robey P. Marrow stromal stem cells. J Clin Invest 2000; 105: 1663-8.

[9] Friedenstein AJ. Stromal mechanisms of bone marrow: cloning in vitro and retransplantation in vivo. Haematol Blood Transfus 1980; 25: 19-29.

[10] Friedenstein AJ, Chailakhjan RK, Lalykina KS. The development of fibroblast colonies in monolayer cultures of guinea-pig bone marrow and spleen cells. Cell Tissue Kinet 1970; 3: 393-403.

[11] Haynesworth SE, Baber MA, Caplan AI. Cell surface antigens on human marrow-derived mesenchymal cells are detected by monoclonal antibodies. Bone 1992; 13: 69-80.

[12] Izadpanah R, Joswig T, Tsien F, Dufour J, Kirijan JC, Bunnell BA. Characterization of multipotent mesenchymal stem cells from the bone marrow of rhesus macaques. Stem Cells Dev 2005; 14: 44051.

[13] Owen M, Friedenstein AJ. Stromal stem cells: marrow-derived osteogenic precursors. Ciba Found Symp 1988; 136: 42-60.

[14] Pittenger MF, Mackay AM, Beck SC, et al. Multilineage potential of adult human mesenchymal stem cells. Science 1999; 284: 143-7.

[15] Prockop DJ. Marrow stromal cells as stem cells for nonhematopoietic tissues. Science 1997; 276: 71-4.

[16] Haynesworth SE, Goshima J, Goldberg VM, Caplan AI. Characterization of cells with osteogenic potential from human marrow. Bone 1992; 13: 81-8

[17] Noth U, Osyczka AM, Tuli R, Hickok NJ, Danielson KG, Tuan RS. Multilineage mesenchymal differentiation potential of human trabecular bone-derived cells. J Orthop Res 2002; 20: 1060-9.

[18] Tuli R, Seghatoleslami MR, Tuli S, et al. A simple, high-yield method for obtaining multipotential mesenchymal progenitor cells from trabecular bone. Mol Biotechnol 2003; 23: 37-49.

[19] Sakaguchi Y, Sekiya I, Yagishita K, Ichinose S, Shinomiya K, Muneta T. Suspended cells from trabecular bone by collagenase digestion become virtually identical to mesenchymal stem cells obtained from marrow aspirates. Blood 2004; 104: 2728-35.

[20] Xiao Y, Haase H, Young WG, Bartold PM. Development and transplantation of a mineralized matrix formed by osteoblasts in vitro for bone regeneration. Cell Transplant 2004; 13: 15-25.

[21] Nakahara H, Bruder SP, Haynesworth SE, et al. Bone and cartilage formation in diffusion chambers by subcultured cells derived from the periosteum. Bone 1990; 11: 181-8.

[22] O'Driscoll SW, Saris DB, Ito Y, Fitzimmons JS. The chondrogenic potential of periosteum decreases with age. J Orthop Res 2001; 19: 95-103.

[23] Zarnett R, Salter RB. Periosteal neochondrogenesis for biologically resurfacing joints: its cellular origin. Can J Surg 1989; 32: 171-4.

[24] Fukumoto T, Sperling JW, Sanyal A, et al. Combined effects of insulin-like growth factor-1 and transforming growth factor-beta1 on periosteal mesenchymal cells during chondrogenesis in vitro. Osteoarthritis Cartilage 2003; 11: 55-64.

[25] De Ugarte DA, Morizono K, Elbarbary A, et al. Comparison of multi-lineage cells from human adipose tissue and bone marrow. Cells Tissues Organs 2003; 174: 101-9.

[26] Dragoo JL, Samimi B, Zhu M, et al. Tissue-engineered cartilage and bone using stem cells from human infrapatellar fat pads. J Bone Joint Surg Br 2003; 85: 740-7.

[27] Liu TM, Martina M, Hutmacher DW, Hui JH, Lee EH, Lim B. Identification of common pathways mediating differentiation of bone marrow- and adipose tissue-derived human mesenchymal stem cells into three mesenchymal lineages. Stem Cells 2007; 25: 750-60.

[28] Sakaguchi Y, Sekiya I, Yagishita K, Muneta T. Comparison of human stem cells derived from various mesenchymal tissues: superiority of synovium as a cell source. Arthritis Rheum 2005; 52: 2521-9.

[29] Yoshimura H, Muneta T, Nimura A, Yokoyama A, Koga H, Sekiya I. Comparison of rat mesenchymal stem cells derived from bone marrow, synovium, periosteum, adipose tissue, and muscle. Cell Tissue Res 2007; 327: 449-62.

[30] Jankowski RJ, Deasy BM, Huard J. Muscle-derived stem cells. Gene Ther 2002; 9: 642-7. 
[31] Noort WA, Kruisselbrink AB, in't Anker PS, et al. Mesenchymal stem cells promote engraftment of human umbilical cord bloodderived CD34(+) cells in NOD/SCID mice. Exp Hematol 2002; 30: 870-8.

[32] Miura M, Gronthos S, Zhao M, et al. SHED: stem cells from human exfoliated deciduous teeth. Proc Natl Acad Sci USA 2003; 100: $5807-12$

[33] Ferrari G, Cusella-De Angelis G, Coletta M, et al. Muscle regeneration by bone marrow-derived myogenic progenitors. Science 1998; 279: 1528-30.

[34] Gimble JM, Robinson CE, Wu X, Kelly KA. The function of adipocytes in the bone marrow stroma: an update. Bone 1996; 19: 421-8.

[35] Lee KL, Aubin JE, Heersche JN. beta-Glycerophosphate-induced mineralization of osteoid does not alter expression of extracellular matrix components in fetal rat calvarial cell cultures. J Bone Miner Res 1992; 7: 1211-9.

[36] Mackay AM, Beck SC, Murphy JM, Barry FP, Chichester CO, Pittenger MF. Chondrogenic differentiation of cultured human mesenchymal stem cells from marrow. Tissue Eng 1998; 4: 415-28.

[37] Young RG, Butler DL, Weber W, Caplan AI, Gordon SL, Fink DJ. Use of mesenchymal stem cells in a collagen matrix for Achilles tendon repair. J Orthop Res 1998; 16: 406-13.
[38] Gronthos S, Franklin DM, Leddy HA, Robey PG, Storms RW, Gimble JM. Surface protein characterization of human adipose tissue-derived stromal cells. J Cell Physiol 2001; 189: 54-63.

[39] Alsalameh S, Amin R, Gemba T, Lotz M. Identification of mesenchymal progenitor cells in normal and osteoarthritic human articular cartilage. Arthritis Rheum 2004; 50: 1522-32.

[40] Majumdar MK, Thiede MA, Mosca JD, Moorman M, Gerson SL. Phenotypic and functional comparison of cultures of marrowderived mesenchymal stem cells (MSCs) and stromal cells. J Cell Physiol 1998; 176: 57-66.

[41] Barry FP, Murphy JM. Mesenchymal stem cells: clinical applications and biological characterization. Int J Biochem Cell Biol 2004; 36: 568-84.

[42] Deans RJ, Moseley AB. Mesenchymal stem cells: biology and potential clinical uses. Exp Hematol 2000; 28: 875-84

[43] Johnstone B, Hering TM, Caplan AI, Goldberg VM, Yoo JU. In vitro chondrogenesis of bone marrow-derived mesenchymal progenitor cells. Exp Cell Res 1998; 238: 265-72.

[44] Yoo JU, Barthel TS, Nishimura K, et al. The chondrogenic potential of human bone-marrow-derived mesenchymal progenitor cells J Bone Joint Surg Am 1998; 80: 1745-57.

[45] Goodell MA, Jackson KA, Majka SM, et al. Stem cell plasticity in muscle and bone marrow. Ann N Y Acad Sci 2001; 938: 208-18; discussion 218-20.

(c) Yameen et al.; Licensee Bentham Open.

This is an open access article licensed under the terms of the Creative Commons Attribution Non-Commercial License (http: //creativecommons.org/licenses/ by-nc/3.0/) which permits unrestricted, non-commercial use, distribution and reproduction in any medium, provided the work is properly cited. 